\title{
Relationship Between HIV and Nutrition
}

\author{
Sivakumar $T^{1 *}$, Vanaja $P^{2}$, Sasikala. $S^{3}$, Vasanthi. $R^{4}$ \\ ${ }^{1}$ Professor, Department of Pharmaceutical Chemistry, Nandha College of Pharmacy, \\ Erode, Tamilnadu, Email: sivancp2021@yahoo.co.in \\ ${ }^{2}$ Assistant Professor, Department of Pharmaceutical Chemistry, Nandha College of \\ Pharmacy, Erode, Tamilnadu, Email: vanaja@nandhapharmacy.org \\ ${ }^{3}$ Assistant Professor, Department of Pharmaceutical Analysis, Nandha College of \\ Pharmacy, Erode, Tamilnadu, Email: sasikalams00101@gmail.com \\ ${ }^{4}$ Professor, Department of Child Health Nursing, Nandha College of Nursing, Erode, \\ Tamilnadu, Email: rvasanthincn@gmail.com \\ ${ }^{*}$ Corresponding Author
}

\begin{abstract}
HIV is a non-curable disease which affects the immune system of the human body. There is a proportional relationship between HIV virus and the nutrition. This disease affects the food intake in the infected person that leads to malnutrition. In this paper general understanding of nutrition is discussed and also gives the brief explanation on the role of nutrition in the management of HIV/AIDS.
\end{abstract}

Keywords: non-curable, HIV, nutrition.

\section{Introduction}

The human immunodeficiency virus (HIV) is a retro virus. The virus builds upon RNA rather than DNA. The RNA virus in $120 \mathrm{~nm}$ in diameter and icosahedral symmetry. The virus directly affects the immune system of the body by invading the T-lymphocytes and other white blood cells with CD4 receptors on its surface.

The virus breaks the bond happening between the lymphocytes and the CD4 cells causing decrease in the immune power in the body. HIV integrates into the cell DNA and turns the cell into virus generating factory. After the breakout it destroys the cell and move to the next cell. In this way it invades the cell one by one and destroys the cells causing degradation in the body.

The virus thus cause the disease called Acquired immune deficiency syndrome (AIDS). This disease limits the body ability to fight against the virus and stops the function of immune system. The person infected with this AIDS has very weak immune system. This is a non- curable disease. This cause fatal effect in the body condition.

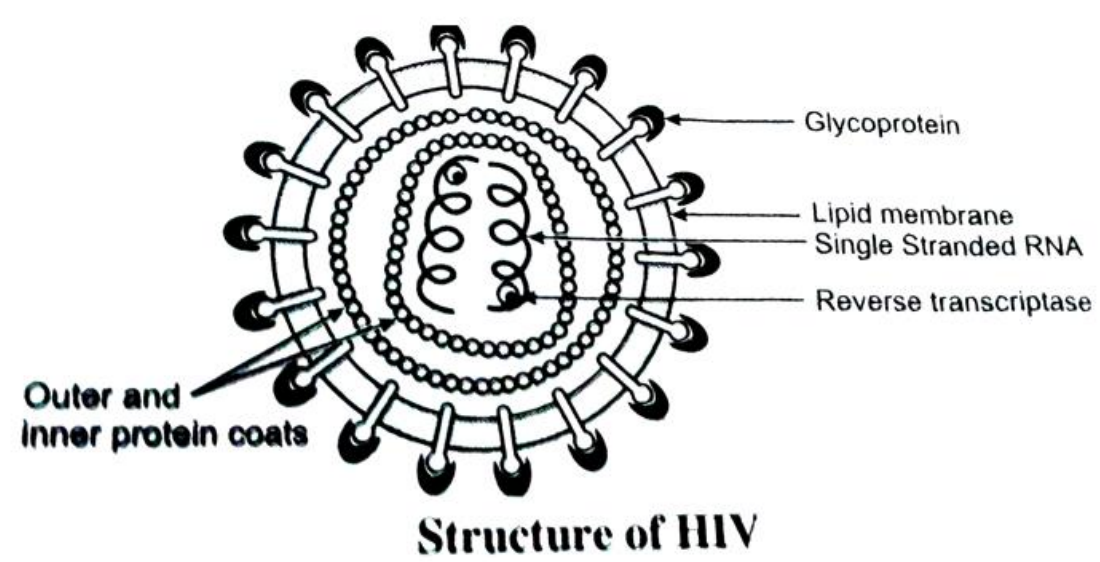

Fig. 1: Structure of HIV

One of the main cause of immune weakness is the lack of nutrition. Nutrition is the process by which the body utilizes the food intake by the person. The body absorb the nutrition by digesting the food. The body uses the nutrition and eliminates the waste from food. When the process is complete the body immune 
system work properly. If there is any break in the absorption process of nutrition it cause malnutrition. Since the virus affects the cell the absorption process breaks and the body immune system weakens. Keeping the immune system strong is very important when the person is infected with HIV. The food we eat contain protein, fats, carbohydrates, vitamins, minerals and water. Proteins are considers as the building blocks of our body. Fats and carbohydrates provide us necessary energy. Vitamins and minerals are responsible in releasing of the energy. All the above are considers as nutrition. They work as a team to provide necessary function of the body. Even if one of the nutrient is insufficient then it cause malfunction of body even though other are high. So in order to maintain healthy immune system all the nutrient should be in appropriate level.
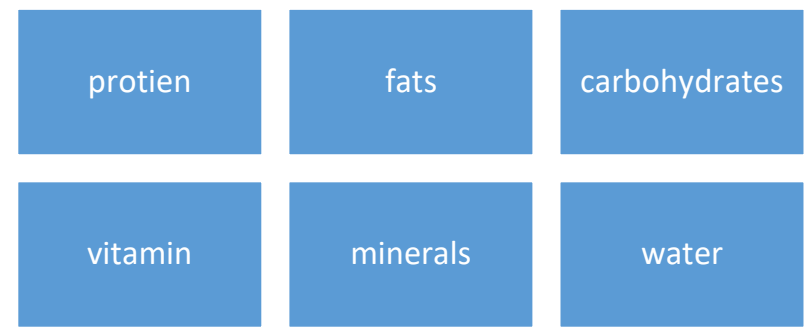

Fig. 2: Team nutrition

The need of good nutrition is important because it helps us to:

- Replace lost nutrition

- Prevent tiredness, weight loss and malnutrition

- Decrease the risk of infection

- Improve response to the medicine while in treatment

\section{HIV and nutrition}

The consequences of HIV on weight-reduction plan are maximum important withinside the early ranges of infection, whilst the inflamed person's repute can be uncertain to the patient. When the frame is inflamed with HIV, the immune machine has to paintings tougher to fight infection. This has an effect on dietary repute because it increases power and nutrient desires. An growth in resting power expenditure, decreases in meals intake, dietary mal absorption, and metabolic adjustments normal in AIDS sufferers might also additionally bring about weight reduction and wasting. Nutritional help has been proposed as the appropriate method to assembly the power and protein desires of PLHIV who're regularly confronted with full-size strain. Deprivation, financial suffering, stigmatization, hunger, and meals scarcity are all examples of deprivation. Among those are meals and dietary help. evaluation, counselling, and guide, in addition to specialised nutritional dietary supplements connections to meals safety and livelihoods applications The advertising and marketing of domestically handy counselling and guide offerings is one of the counselling and guide components. Foods that in shape the dietary desires of HIV of their day by day lives Physiologic condition, age, and intercourse In addition, help is presented withinside the shape of a complete method that consists of different factors of care including the remedy of opportunistic infections, strain management, bodily activity, emotional, and intellectual fitness Counseling and help on a mental and non secular level.

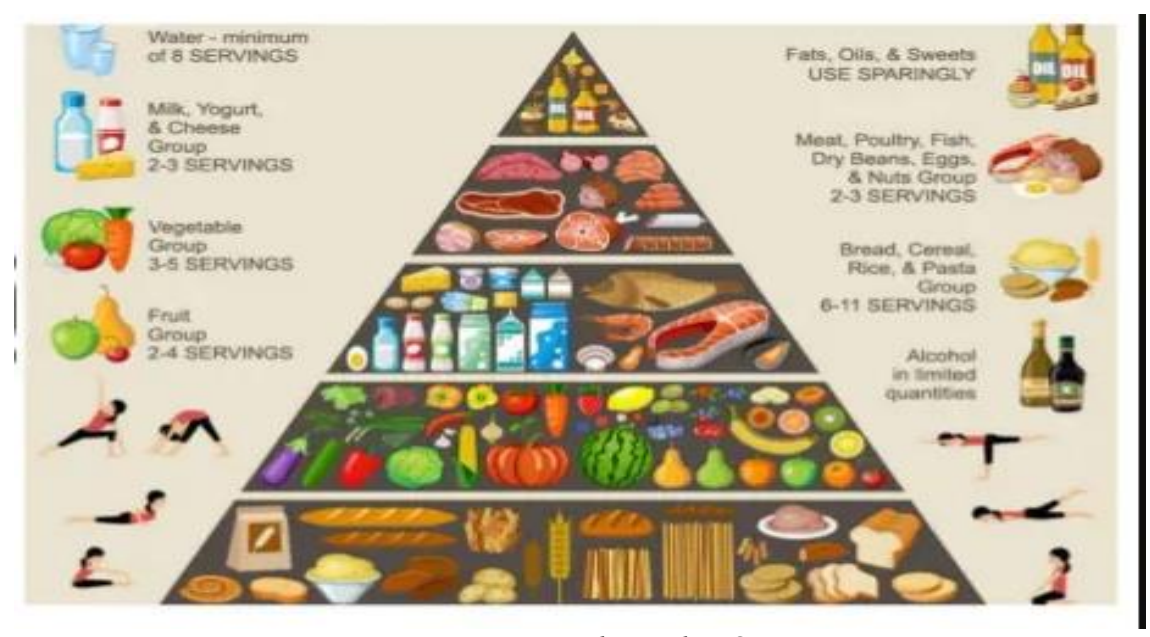

Fig. 3 : Nutritional intake for HIV 
When properly implemented, the assistance can improve the cure rate of HIV-related illnesses, as well as prevent weight loss, diarrhea and digestive pain. Due to fat malabsorption and providing HIV with the strength, skills and resources it needs to thrive.

HIV symptomatic adults' power necessities are 20 percentage to 30 percentage greater than noninflamed people of the equal age, sex, and gender for the duration of AIDS. Amount of bodily activity. For asymptomatic people, however, to preserve frame weight, power necessities are in all likelihood to be raised through $10 \%$. As properly as bodily activities. In addition, HIV calls for a whole lot of power. The dosage for unwell kids who're dropping weight have to be raised through 50 percentage to one hundred percentage. Weight loss and losing are early degrees, consistent with studies. HIV contamination in adults has bad repercussions because of insufficient weightreduction plan. This is a horrible situation. Nutrition increases the chance of opportunistic infections and decreases the time spent alive. Furthermore, scientific effects are lower, and there's a hyperlink among the two. Adults with micronutrient deficiencies have a tremendous chance of mortality. The immune machine calls for micronutrients which includes diet A, B-complex, C, and E, in addition to selenium and zinc, to combat contamination. Deficits in those micronutrients might also additionally make contributions to the path of HIV contamination in inflamed humans and are usual in HIV sufferers because of bad nutrition. To maintain fitness and first-class of lifestyles in the course of the early degrees of contamination, right weight-reduction plan is essential. Daily micronutrient supplementation accelerated frame weight and mass, diminished HIV RNA levels, superior CD4 mobileular counts, and decreased the incidence of opportunistic infections in a smaller scientific trial. A similar studies completed on a larger scientific trial amongst grownup AIDS sufferers discovered that people with low CD4 mobileular counts lived longer, had higher beginning outcomes, and had much less mother-to-toddler transmission. Malnutrition in HIV is because of hunger, cachexia, or a aggregate of the two. Starvation is because of a loss of vitamins or mal-absorption, or both, and may be restored with suitable nourishment. Rather than muscular mass, hunger induces fats mass loss. If now no longer addressed, however, fats loss can improve to muscle loss. Cachexia is described as a lack of muscles this is out of share to general weight reduction and isn't always reversible with right weight-reduction plan. The clinical motive of muscles loss ought to be diagnosed and rectified. A right dietary care and aid application can decorate the first-class of lifestyles of these residing with HIV. It Furthermore, powerful dietary care and aid packages can assist HIV-inflamed humans preserve a healthful frame weight and strength, update misplaced nutrients and minerals, enhance immune machine functions, postpone the development of HIV to AIDS, enhance remedy response, lessen money and time spent on fitness care, and maintain HIV-inflamed humans active, productive, and able to developing meals and worrying for themselves, their kids, and family.

\section{HIV and Antiretroviral Drugs}

Highly active antiretroviral medical aid (HAART) improves nutritionary standing in spite of the aspect effects and metabolic complications. The side effects of ARV embody nausea, and unconditioned reflex. This could have an effect on adherence to therapy, notably within the 1st months of treatment. Also, wasting still develops in some patients on ARV. Additionally, bound metabolic complications like derangements in aldohexose and lipide metabolism and potable blood disease are related to the utilization of certain ARV medicine. Use of haart drug cocktail highly active antiretroviral to treat HIV sickness has been productive in rising immune status for those who have access to the medicine and may tolerate them. These medications have given folks with HIV infection the hope of living out a traditional generation. Maintaining an honest physical look and overall health square measure important issues for many patients. Anti-retroviral therapy is once medicine square measure used for the treatment of HIV/AIDS. These medicine work by suppressing the action of 1 or the opposite of 2 microorganism enzymes essential for replication of the HIV virus. The presently out there HIV antiviral medicine will improve the standard of lifetime of somebody infected with HIV and facilitate somebody to stay well for much longer than they might while not the medicine. These medicine square measure used for treatment and not cure. The United Nations agency Technical conductive cluster on Nutrition and HIV/AIDS addressed a number of metabolic complications related to the utilization of bound sorts of ART, as well as derangement in aldohexose and lipide metabolism, bone metabolism and potable blood disease documented in industrialized countries. The consultation Chapter a pair of ninety three emphasized the necessity for proof to enhance management of those metabolic abnormalities in patients receiving ART. Explicit thought was given to gaps in data about ART use in populations wherever deficiency disease is endemic. ART is more practical once anti-retroviral medicine from totally different categories square measure used in combination. As a result of the virus can develop resistance if only 1 drug is used. These medicine are often offered as one drug regime (monotherapy), dual medical aid or triple medical aid or extremely active antiretroviral medical aid (HAART). The single drug medical aid isn't counseled for the treatment of HIV infection as no single antiretroviral drug used up to now has provided decent, long-lived suppression of HIV replication. 
Monotherapy will, however, play a crucial role within the interference of mother-to-child transmission. Twin medical aid is moderately effective. It's not the quality care however is healthier than no medical aid at all and will be thought of in patients unable to afford extremely active antiretroviral therapy. Triple mixtures or medicine is that the combination of 3 synergistic antiretroviral agents. It remains the quality of care and substantial reductions in medication costs still build triple-drug regimens additional affordable.

The anti-retroviral medicine are abundant lower costs to folks living with HIV/AIDS. a number of the triple combination medicine embody NRTI, AZT, didnosine, ddl, stavudine, d4T, lamivudine, 3TC, indinavir, neverapine and efavirenz. The benefits of antiretroviral medical aid embody lower mortality, improved quality of life, reduced hospitalization prices, and enlarged labour-force productivity, potential reductions in new infections because of lower microorganism load and enlarged stability and longevity of families with fewer orphans (IAE and UNFPA 2003). In Africa, there's AN evidence-based analysis on the importance of nutrition in improving interference of the sickness, treatment and look after PLHIV. Nutritionary interventions involving foodbased approaches and substance supplementation ought to be integrated into all HIV treatment programs. This may enhance ART acceptableness, adherence and effectiveness. However, appropriate ways for nutritionary counseling and management still got to be investigated in resource restricted countries.

\section{Nutrition requirement for HIV}

The person affected from HIV should maintain good nutrition level in order to meet the requirement of the drug to work properly and also to maintain good stability of the body. The individual should consume about 20 to 30 percent more energy. The patient should limit the intake of oil and fat. There should be a good intake of micro nutrient in order to maintain stable energy release. The energy requirement should be increased 10 percent more than normal level. The protein intake should not be more than 15 to 20 percent in total calories. Saturated fat should be 7 percent in total calories. Mono saturated fat should be more than 10 percent in total calories. Ploy unsaturated fat should be 10 percent less than total intake of the calories.

Nutritional counselling should be given to the patient in order to make them aware of the requirement of their food intake. Complementary foods can also be added like curd, fruits and other locally available foods as per the requirement. The protein intake should be increased to avoid nutritional recovery syndrome. There should be slow and steady improvement in the feeds. Regular exercise is must to keep the body healthy. Exercise strengthens the muscles which helps to improve the immune system. Micro nutrient intake should be given importance as other nutrients to maintain good balance in the immune system.

\section{Conclusion}

A good diet gives good nutrition. Good nutrition has several benefits to improve the immune system and to have stable health and to have good resistance against the HIV infection. Better immune system makes the body stronger to fight against the disease. Good nutrition helps to manage HIV symptom and reduce the complication due to infection. Having good food with nutrient in said amount helps to process the medication and help the body to respond to the drug in a better way and also reduce the side effect caused by the medicine. Carbohydrates provide body with energy, protein provide better immune system by building better body, intake of right fat gives extra energy, vitamins and minerals regulates body process. By concluding it shows that right amount of nutrition can help to maintain the HIV infection and also to lead a healthy life.

\section{References}

1. Abdale, F. \& Kraak, V. 1995, Community-based nutrition support for people living with HIV and AIDS: A technical assistance manual, God's Love We Deliver, Inc, New York.

2. Awour, L., Achilili, F., \& Amolo, D. 1998, Nutrition for people with HIV/AIDS as health guard. Paper presented at the XII International AIDS Conference Geneva, Swizerland.

3. Babamento, G. \& Kotler, D. 1997. Malnutrition in HIV infection. American Journal of Nutrition, 26, 393-415 Barbour, R. 1999. The case for combining qualitative and quantitative approaches in health services research. Journal of Health Services Research and Policy, 4, (1) 39-43 Barlow, D. \& Hursen, M. 1984, Single Case Experimental Designs: Strategies for studying Behaviour Change. Pergamon : New York.

4. Baum, M. \& Shor-Posner, G. 1995. Micronutrients and HIV disease progression. America Journal of Nutrition, 9, 1051-1056

5. Bijlsma, M. 2000, Nutritional care and support for people living with HIV: Review of the literature, initiatives, and educational materials in sub-Saharan Africa, FAO,

6. Rome. Bogden, J., Kemp, FW., \& Han, S. 2000. Status of selected nutrients and progression of Human Immunodeficiency Virus Type 1 Infection. America Journal of Nutrition, 72, (3) 809-815

7. Roper, W.L. 1991. Current approaches to prevention of HIV infections. Public Health Reports, 106, (2) 111-115

8. Almeida, S. M. (2015). Cerebrospinal fluid analysis in the HIV infection and compartmentalization of HIV in the central nervous system. Arq Neuropsiquiatr, 73(7), 624-629. doi:10.1590/0004-282×20150071 
9. Anderson, D. J., Politch, J. A., Nadolski, A. M., Blaskewicz, C. D., Pudney, J., \& Mayer, K. H. (2010). Targeting Trojan Horse leukocytes for HIV prevention. AIDS (London, England), 24(2), 163-187. doi:10.1097/QAD.0b013e32833424c8.
10. The Kirby Institute for infection and immunity in society UoNSWSA. Annual Surveillance reports 20012010. University of New South Wales, 2001-2010. 